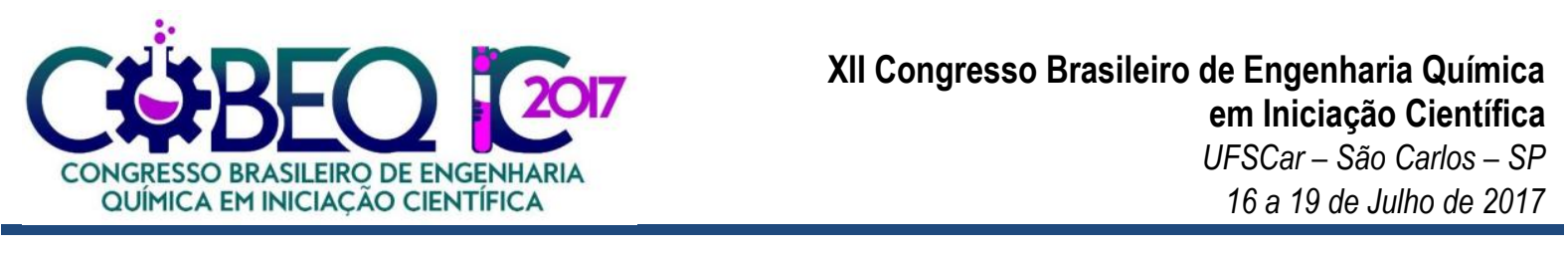

\title{
CARACTERIZAÇÃO FÍSICA E CINÉTICA DE SECAGEM DE SORGO (SORGHUM BICOLOR L. MOENCH)
}

\author{
G.F. ESTECA ${ }^{1}$, R. C. BRITO ${ }^{1}$ e R. BÉTTEGA ${ }^{1}$ \\ ${ }^{1}$ Universidade Federal de São Carlos, Centro de Ciências Exatas e de Tecnologia, Departamento \\ de Engenharia Química \\ E-mail para contato: bettega@ufscar.br
}

\begin{abstract}
RESUMO - Neste trabalho, foi realizado um estudo da caracterização física e da secagem de sorgo [Sorghum bicolor (L.) Moench] em estufa. Foram determinadas as dimensões, densidade bulk e aparente, esfericidade, fator de forma, ângulo de repouso e porosidade do leito. Após a umidificação do material, foi feita a análise da cinética de secagem do sorgo em estufa. Foram utilizadas três temperaturas diferentes: $40^{\circ} \mathrm{C}, 50^{\circ} \mathrm{C}$ e $60^{\circ} \mathrm{C}$, em intervalos de tempo uniformes, por 520 minutos. Com os dados experimentais foi possível construir as curvas da cinética da secagem e ajustá-las aos modelos semi-empíricos de Lewis, Page, Henderson e Pabis e Overhults. Para avaliar os ajustes foram empregados o coeficiente de correlação $\left(\mathrm{R}^{2}\right)$, a raíz quadrada do erro médio (RMSE) e Chi-quadrado $\left(\chi^{2}\right)$. Os modelos de Page e Overhults foram aqueles que apresentaram melhores resultados.
\end{abstract}

\section{INTRODUÇÃO}

O sorgo [Sorghum bicolor (L.) Moench] chegou a ser o quinto cereal mais importante do mundo. Sua cultura tem custo relativamente baixo comparado ao milho, com poucos problemas de pragas e doenças. $\mathrm{O}$ sorgo possui em seus colmos grandes quantidades de açúcares como sacarose, frutose e glicose, característica que torna o caldo extraído facilmente fermentado para a produção de etanol, tal como o milho e a cana. Além disso, o sorgo possui uma maior rapidez no ciclo (maturidade entre 120 e 130 dias) em comparação com estas culturas (EMBRAPA, 2014, BRITO, 2017).

A qualidade e conservação dos grãos e sementes é função dos fatores envolvendo a pré colheita, a colheita e a pós colheita. A secagem constitui uma etapa importante na conservação de grãos e sementes. Corretamente conduzida, pode representar uma grande economia no processo, auxiliando na redução dos custos energéticos bem como na minimização de perdas de produto, dentre outras vantagens. Diante do contexto apresentado, onde a demanda por menores custos de produção e conservação é um objetivo a ser alcançado, as particularidades e dificuldades dos procedimentos envolvendo o processo de secagem constituem grandes motivadores para a pesquisa acerca desta operação aplicada à grãos e sementes. $\mathrm{O}$ conhecimento das características físicas do material a ser seco é um dos fatores fundamentais para a análise do processo de secagem. Dados das propriedades do material permitem a realização de cálculos de dimensionamento de secadores e a avaliação dos processos de transferência de calor e massa (PEREIRA, 2010). 
Portanto, o objetivo deste trabalho consistiu em determinar as características físicas do sorgo e sua cinética de secagem em estufa. Os dados experimentais obtidos no processo de secagem foram ajustados aos modelos semi-empíricos de Lewis, Page, Henderson e Pabis e Overhults, a fim de que fosse determinado o modelo que melhor representasse os resultados.

\section{MATERIAIS E MÉTODOS}

\subsection{Caracterização física}

Analogamente ao método utilizado por Pereira (2010), as determinações da largura $(L)$, altura $(W)$ e espessura $\left(T^{\prime}\right)$ dos grãos foram feitas com a utilização de um paquímetro. Em conjunto, utilizou-se o software de análise de imagens Image Pró-Plus ${ }^{\circledR}$ para a estimativa do perímetro, área projetada e redondeza dos grãos. Ambos os procedimentos foram empregados em um conjunto de 20 grãos, sendo obtidas e apresentadas as médias aritméticas das medições realizadas. A Equação (1) foi aplicada para o cálculo da esfericidade do material (MOHSENIN, 1986):

$$
\phi=\frac{\text { diâmetro geométrico médio }}{\text { diâmetro maior }}=\frac{\sqrt[3]{W \cdot T^{\prime} \cdot L}}{L}
$$

A determinação da massa específica aparente $\left(\rho_{a p}\right)$ foi feita através de picnometria líquida em água destilada. O método possui embasamento teórico no princípio de Archimedes e consiste basicamente na imersão da amostra em um recipiente ocupado por um fluído. A densidade bulk $\left(\rho_{b}\right)$ foi estimada por meio da razão entre a massa de grãos em um recipiente graduado cilíndrico (proveta de 2 litros), os quais foram precipitados de uma altura fixa, e o volume do leito empacotado formado após a sedimentação dos grãos no recipiente.

A porosidade bulk foi calculada empregando-se os valores medidos das densidades aparente e bulk do material aplicando-se a seguinte equação (MOHSENIN, 1986):

$$
\varepsilon_{b}=1-\frac{\rho_{b}}{\rho_{a p}}
$$

Para a obtenção da umidade inicial do sorgo utilizou-se o método gravimétrico (estufa à $105^{\circ} \mathrm{C}$ pelo período de 24 horas). A umidificação do material foi realizada a fim de que fosse atingida uma umidade de $30 \%$ em base úmida, aplicando-se metodologia análoga à utilizada por Brito (2017).

\subsection{Cinética de Secagem}

Para a obtenção das curvas de secagem foi utilizada uma estufa de circulação e renovação de ar TECNAL - TE-394/I, com uma velocidade de escoamento de ar de $1 \mathrm{~m} / \mathrm{s}$. Inicialmente, três placas petris foram pesadas e em seguida preenchidas com uma camada de material umidificado pelo método anteriormente descrito. Após serem pesadas novamente, seguiram para a estufa acima referida aquecida e estabilizada. Estas placas foram retiradas da estufa e pesadas em intervalos de tempo de 10 minutos. Após 60 minutos de experimento, aumentou-se os intervalos para 20 minutos. Os experimentos transcorreram até que a variação de massa entre os intervalos não fosse significativa, obtendo-se assim um equilíbrio dinâmico. 
As cinéticas de secagem foram representadas pelo adimensional de umidade (MR), calculado por meio da Equação (3), em função do tempo decorrido.

$$
M R=\frac{X_{t}-X_{e q}}{X_{0}-X_{e q}}
$$

Onde $X_{\mathrm{t}}$ é a umidade média em um determinado tempo do processo (média aritmética dos valores de umidade obtidos para as 3 placas petri), $X_{0}$ é a umidade inicial e $\mathrm{X}_{\text {eq }}$ é a umidade no equilíbrio dinâmico.

Para a obtenção da curva teórica de secagem de sementes de sorgo, os dados experimentais obtidos foram ajustados aos modelos apresentados na Tabela 1.

Tabela 1 - Critérios estatísticos de ajuste dos modelos de cinética de secagem.

\begin{tabular}{ccc}
\hline Nome do Modelo & Equação de cinética de secagem \\
\hline Page & $M R=\exp \left(-K_{p} \cdot t^{n p}\right)$ \\
Henderson e Pabis & $M R=a \cdot \exp \left(-K_{H P} \cdot t\right)$ \\
Overhults & $M R=\exp \left(-\left(K_{o} \cdot t\right)^{n o}\right)$ \\
Lewis & $M R=\exp \left(-K_{L} \cdot t\right)$ & $(5)$ \\
\hline
\end{tabular}

A análise da qualidade do ajuste foi feita com base no coeficiente de correlação $\left(R^{2}\right)$, na raiz quadrada do erro médio (RMSE) e no chi-quadrado $\left(\chi^{2}\right)$.

\section{RESULTADOS}

Na Tabela 2 são apresentados os resultados obtidos na caracterização física do material.

Tabela 2 - Resultados da caracterização do sorgo.

\begin{tabular}{cc}
\hline Propriedade & Valor \\
\hline $\mathrm{L}(\mathrm{mm})$ & 3,97 \\
$\mathrm{~W}(\mathrm{~mm})$ & 3,46 \\
$\mathrm{~T}^{\prime}(\mathrm{mm})$ & 2,24 \\
perímetro $(\mathrm{mm})$ & 11104 \\
área Projetada $\left(\mathrm{mm}^{2}\right)$ & 9954 \\
circularidade & 1048 \\
$\Phi$ & 0,79 \\
$\rho_{\text {bulk }}\left(\mathrm{g} / \mathrm{cm}^{3}\right)$ & 0,85 \\
$\rho_{\text {aparente }}\left(\mathrm{g} / \mathrm{cm}^{3}\right)$ & 1197 \\
porosidade & 0.29 \\
\hline
\end{tabular}

Na Figura 1 são apresentados os dados da umidade adimensional (MR) em função do tempo de secagem, juntamente com os dados de taxa de secagem em função do tempo. 

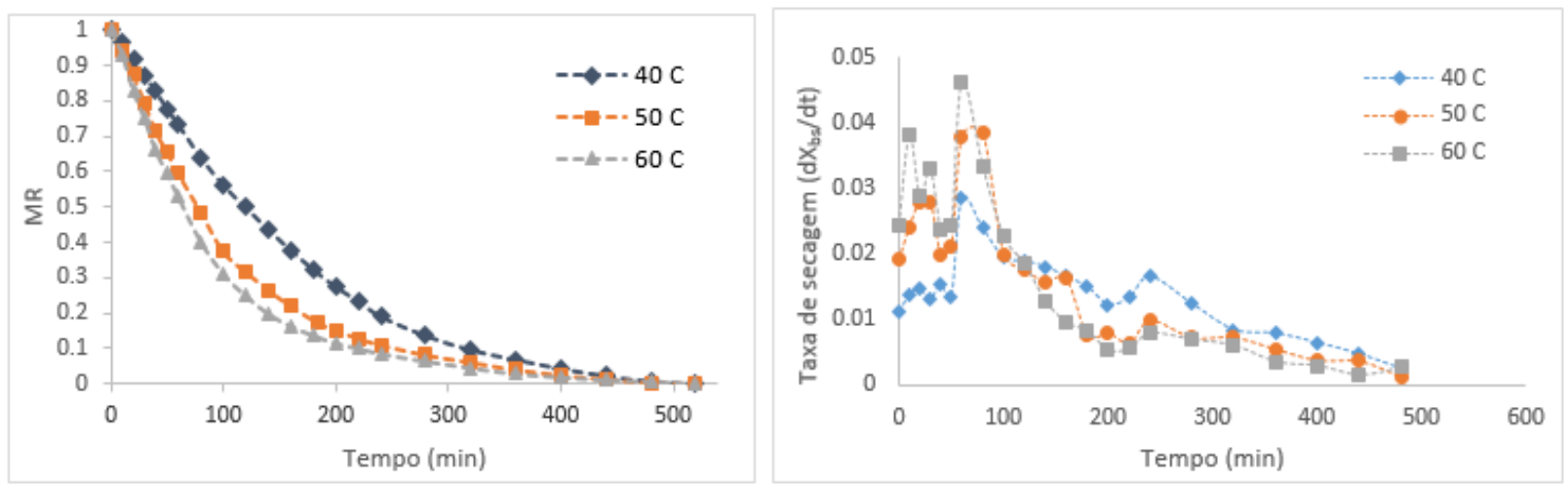

Figura 1 - (a) Umidade adimensional (MR) em função do tempo de secagem. (b) Taxa de secagem em função do tempo de secagem.

Na Figura 1.a. observou-se um efeito significativo da temperatura no processo, pois com o aumento da temperatura ocorreu também uma redução do tempo de secagem para que uma mesma umidade fosse atingida. Essa diminuição do tempo de secagem pode ser justificada pelo fato de que, com o aumento da temperatura uma maior quantidade de energia térmica é fornecida ao sistema.

Apesar das flutuações que provavelmente podem ter sido ocasionadas pelo erro experimental e constante abertura da estufa para que as medidas fossem realizadas, observa-se na Figura 1.b. uma tendência decrescente da taxa de secagem na maior parte do tempo de processo analisado. Isso sugere que a secagem do sorgo seja controlada pelos mecanismos internos de transferência de massa. As características heterogêneas do meio poroso do grão, juntamente com outros fatores, oferecem resistências ao fluxo de umidade do interior para superfície dos grãos, que resulta no decréscimo da taxa de secagem.

Na Tabela 3, são apresentados os resultados obtidos dos ajustes das Equações (4), (5), (6) e (7) aos dados experimentais para as temperaturas de 40,50 e $60^{\circ} \mathrm{C}$.

Tabela 3 - Valores dos critérios estatísticos dos ajustes das equações para as temperaturas 40, 50 e $60^{\circ} \mathrm{C}$.

\begin{tabular}{ccccc}
\hline & $\mathbf{T}_{\mathbf{a r}}\left({ }^{\mathbf{0}} \mathbf{C}\right)$ & $\mathbf{4 0}$ & $\mathbf{5 0}$ & $\mathbf{6 0}$ \\
\hline $\mathrm{R}^{2}$ & Page & 0,99954 & 0,99852 & 0,99786 \\
& Henderson e Pabis & 0,99414 & 0,99848 & 0,99812 \\
& Overhults & 0,99954 & 0,99852 & 0,99786 \\
& Lewis & 0,99018 & 0,99716 & 0,99744 \\
\hline RMSE & Page & 0,02409 & 0,04208 & 0,04908 \\
& Henderson e Pabis & 0,08563 & 0,04316 & 0,04603 \\
& Overhults & 0,02405 & 0,04207 & 0,04904 \\
& Lewis & 0,11346 & 0,06023 & 0,05494 \\
\hline$\chi^{2}$ & Page & 0,00006 & 0,00017 & 0,00023 \\
& Henderson e Pabis & 0,00070 & 0,00018 & 0,00020 \\
& Overhults & 0,00006 & 0,00017 & 0,00023 \\
& Lewis & 0,00123 & 0,00035 & 0,00029 \\
\hline
\end{tabular}


As equações de Page e Overhults apresentaram os maiores valores de $\mathrm{R}^{2}$. A maioria das equações apresentaram valores de RMSE em torno de 0,04 , porém os valores relativos a Page e Overhults foram os mais baixos para a maioria das temperaturas. Quanto ao valor de $\chi 2$, o ajuste de Lewis apresentou o maior valor, de 0,00123, e o ajuste de Page e Overhults novamente foram os menores, não ultrapassando 0,00029 em nenhuma temperatura.

Sendo assim, segundo os critérios adotados, os ajustes de Page e Overhults foram aqueles que melhor ajustaram-se aos dados experimentais. Como K e n são parâmetros dependentes da temperatura, utilizou-se os valores das constantes obtidas pelo ajuste para verificar a adequação do modelo aos dados experimentais. Os gráficos são apresentados na Figura 2.
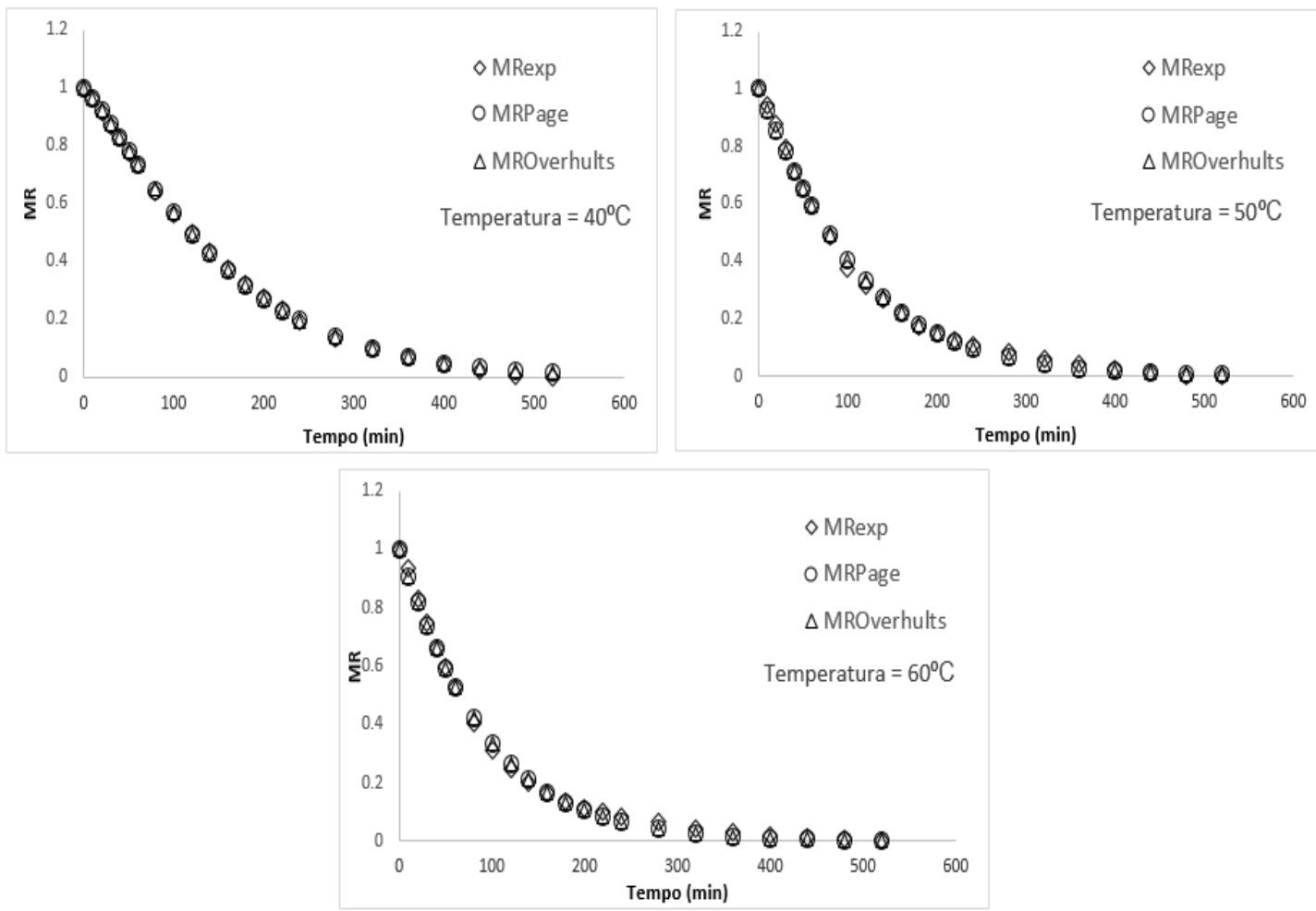

Figura 2 - Gráficos de ajuste dos modelos de Page e Overhults para a temperatura de 40, 50 e $60^{\circ} \mathrm{C}$.

Na Figura 2 verifica-se um ajuste satisfatório dos modelos aos dados experimentais, indicando que ambos os modelos geram curvas de secagem suficientemente próximas das curvas experimentais do processo de secagem de sorgo. Foi possível observar também que, quanto maior a temperatura, maior a divergência dos modelos aos dados experimentais, fato que pode ser observado também pelos valores de $\mathrm{R}^{2}$, RMSE e $\chi^{2}$ apresentados anteriormente na Tabela 3. 


\section{CONCLUSÕES}

Pela análise das curvas de secagem em estufa das sementes, foi possível verificar que a variação de temperatura da estufa acelera o processo de secagem. As curvas de taxa de secagem obtidas sugeriram a predominância dos mecanismos internos de transferência de massa. Concluiu-se também que os modelos de Page e Overhults foram aqueles que melhor se ajustaram aos dados experimentais. Fato comprovado pelos critérios estatísticos: coeficiente de correlação $\left(\mathrm{R}^{2}\right)$, raiz quadrada do erro médio (RMSE) e chi-quadrado $\left(\chi^{2}\right)$.

\section{REFERÊNCIAS}

BRITO, R. C. Estudo energético da secagem de sorgo [Sorghum Bicolor (L) Moench] em leito de jorro. 2017. 119 f. Dissertação (Mestrado em Engenharia Química) - Programa de Pós-Graduação em Engenharia Química, Centro de Ciências Exatas e Tecnologia, Universidade Federal de São Carlos, São Carlos, 2017.

EMBRAPA MILHO E SORGO, 2014, Brasília. Cultivo do Sorgo. Brasília: Sistema de Produção, 2014.

MOHSENIN, N. N. Physical properties of plant and animal materials. 1. ed. New York: Gordon and Breach, 1986. 841 p.

PEREIRA, A.V. Caracterização e Secagem de Sementes de Painço (Setaria itálica L.).2010. 92 f. Dissertação (Mestrado em Engenharia Química) - Departamento de Engenharia Química, Universidade Federal de São Carlos, São Carlos, 2010. 